\title{
La comunicación visual a través de Pepe Mexía y Ricardo Rendón, $1915-1930$
}

Visual communication through Pepe Mexía and Ricardo Rendón, 1915-1930

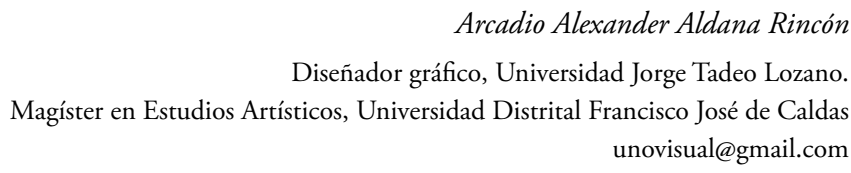

Artículo de investigación

DOI: http://dx.doi.org/10.15332/s2339-3688.2016.0001.02

Fecha de recepción: Septiembre 9 de 2015 • Fecha de aprobación: Mayo 8 de 2016

\section{Resumen}

El pensamiento contemporáneo occidental representado visualmente a través del arte europeo, desarrolla su máxima complejidad en las primeras décadas del siglo XX, en las principales ciudades como Londres, París o Berlín se consolidan posiciones transformadoras en la estética; también la forma de percepción es distinta a los decimonónicos preceptos de la tradicional Academia de Arte. Los artistas colombianos son permeables a estos cambios y el modelo europeo es una fuerte influencia en la conducta social colombiana en la primera mitad del siglo pasado. Dos artistas antioqueños, que desarrollan su trabajo en la década de los veinte y treinta, aplican características visuales conceptualmente modernas basadas en las ideas vanguardistas del arte europeo, apropiando conceptos en el contexto local y ejerciendo en medio de su producción el oficio del diseño gráfico, generando manifestaciones visuales únicas y completamente originales.

Palabras clave: diseño, arte, vanguardia, editorial. 


\begin{abstract}
The contemporary Western thought visually represented through the European art develops maximum complexity in the first decades of the twentieth century, in major cities like London, Paris or Berlin transforming positions are consolidated into the aesthetics, also the way of perception is different from the precepts of the nineteenth century traditional Academy of Art. Colombian artists are permeable to these changes and the European model is a strong influence in Colombian social behavior in the first half of the last century. Two artists, who work in the twenties and thirties, apply conceptually modern visual characteristics based on cutting-edge ideas of European art appropriating concepts in the local context and exercising in the middle of production, the office of design graphic, generating unique and completely original visual manifestations.
\end{abstract}

Keywords: Design, art, vanguard, editorial. 


\section{INTRODUCCIÓN}

La historia del diseño gráfico en Colombia durante años no ha sido abordada como tema de investigación en la academia, por lo tanto determina que los documentos que existen al respecto se encuentren aún sin terminar. Es así como revisando, indagando y analizando desde el conocimiento contemporáneo del diseño, se pueden rastrear aquellos diseñadores gráficos que nunca fueron catalogados como tal porque el término todavía no se usaba, asociándolo con otras prácticas que realizaban y eran muy conocidas, como el caso del campo del arte.

\section{El comienzo}

Colombia ha entrado al siglo XX y se encuentra en una situación precaria a nivel económico y social. No se había acostumbrado a la independencia de los iberos cuando los dirigentes ya estaban peleándose por el poder tratando de organizar y de construir una nación. Estos enfrentamientos constantes claramente identificados por bandos o partidos políticos desangraron al país en varias guerras civiles durante lo que quedaba del siglo XIX hasta la amarga y larga guerra de los Mil Días hacia 1902. Dándole así la bienvenida al nuevo siglo, pobres en arcas administrativas, desolados por la violencia a nivel sicológico y social y en espera del tan anhelado cambio que nos lleve a un mejor futuro, igual de esperado hasta hoy.

Al siguiente año, en 1903, se produce lo que se considera uno de los más grandes desaciertos administrativos, la separación del istmo de Panamá. Favoreciendo los intereses estratégicos americanos para conquistar un punto importantísimo a nivel geográfico que había cobrado mucho valor a finales del siglo XIX, donde se trató y consiguió trazar rutas de cruce que comunicaran a los dos océanos. Siendo esta ruta comercial una de las más codiciadas y competidas del mundo (Revista Semana. Universidad Nacional de Colombia, 2010, p. 16) en aquel momento fue perdida por motivos o intereses particulares que a la larga el país no vio. Este hecho en particular fue duramente criticado en representaciones visuales de toda índole, como por ejemplo la película silente Garras de Oro (Jambrina, 1926), cuya realización 
casi anónima y con estructuras visuales pioneras como el color manual ${ }^{1}$ algunos fotogramas dejan ver claramente el desacierto que casi de inmediato produjo la venta del istmo, así como ilustraciones y reseñas literarias no tan anónimas que circularon durante varios años.

Durante las primeras décadas del nuevo siglo, el territorio nacional todavía estaba en proceso de industrialización y era evidente la fuerte influencia del sistema económico rural y su mala administración, dándole prioridad a los pocos productos exportados y dejando sin impulso el sistema de producción interno. Es en este tiempo donde el café se convierte en un producto insignia de exportación en el país, logrando aceptación en gran parte del territorio nacional, generando su sembrado en los campos colombianos. Comienza entonces la gran época del café y Colombia se convierte en exportador del mejor y más suave café del mundo. Cabe anotar que en este punto de convulsión económica y de tratar de realizar una restauración importante a nivel político después de las guerras civiles del diecinueve, un aspecto importante en el panorama social y político fueron los movimientos obreros e indígenas. Ejemplo desatacado fue Manuel Quintín Lame, líder que generó uno de los grandes levantamientos de la resistencia indígena en la historia del país denunciando la reducción de territorios propios de las comunidades por parte de los terratenientes. Su lucha originaria de la región caucana se extendió a los departamentos del Tolima y Huila desde 1914 hasta que ya entrado los años 40s logra la oficialización de varios resguardos indígenas, un pedazo de tierra que por derecho era suya. Así mismo, la creación del partido Socialista Revolucionario a cabeza de la legendaria María Cano en 1919 impulsa que los obreros en distintas partes del país reclamen mejoras en las condiciones de trabajo y salario. Las repetidas huelgas obreras generan enfrentamientos con el gobierno que terminan en la lúgubre, injusta e impune marcha de los obreros de la United Fruit Company en la costa conocida como la Masacre de las Bananeras en 1928.

1 La coloración manual en la historia del cine tuvo vigencia corta porque no obtuvo el éxito que se esperaba, además de ser muy compleja y dispendiosa la labor. Como lo resume Daniela Stara (2009): "La película revelada era coloreada manualmente, sobre la emulsión, con pinceles muy finos. La coloración era efectuada fotograma por fotograma y este trabajo era ejecutado exclusivamente por mujeres en grandes fábricas". 
Estos sucesos, entre otros, fueron los reflejos constantes en las tres primeras décadas del siglo XX en Colombia, de una sociedad fluctuante en aparente desarrollo pero que evidencia una inacabable turbulencia social, reflejo del mal manejo administrativo del país. La violencia en este aspecto tampoco queda relegada al pasado de las guerras oficiales. Está presente en pequeñas escaramuzas bipartidistas que acumulan progresivamente durante estos años otro rencor exacerbado que estallarán con la muerte de Jorge Eliecer Gaitán, y cuya explosión da como resultado la violencia abierta y descarnada que masivamente desangrará a Colombia en varias etapas encadenadas hasta nuestros días.

\section{Desarrollo}

Las manifestaciones artísticas como la música, la literatura y la escultura, así como la pintura no son ajenas al contexto y ponen de manifiesto su constante desacuerdo con la brutal violencia que crece desmedidamente. Precisamente lo visual, la gráfica y los estamentos pictóricos son un elemento importante en la representación de la situación social política del país. Por ejemplo, una de las obras más reconocidas en la pintura colombiana que visualiza la atrocidad de la violencia es la obra de Alejandro Obregón, Violencia de 1962. Es una temática obligada en los grandes momentos de la pintura nacional, evidenciando no solo la necesidad de plasmar sueños e ideales de sociedad, sino denunciando la realidad que atormenta o ensombrece la cotidianidad. Es importante destacar el papel que ejerce la caricatura en el proceso político y como canal documentalista de los acontecimientos nacionales. La caricatura es una eficaz manera de comunicar visualmente variantes y diferencias físicas que tienen o contienen un sentido simbólico determinado, y sitúa al espectador en el papel del personaje creador de la crítica, pues es este el que decide darles sentido a las características gráficas de su construcción, es decir, a las deformidades. La burla hacia lo diferente hace que la caricatura tenga diferentes matices de comprensión dependiendo de a quién se represente. Como se exalta en la investigación sobre la Historia de la caricatura en Colombia (González, 1989), la fuente estructural de lo caricaturesco es la risa, pero esta risa puede tornarse maliciosa, despectiva o simplemente quedarse con su condición simple de algo exagerado. La asociación con las formas animales tomadas como metáforas de comportamientos específicos 
del personaje, hacen del zoomorfismo una herramienta común en la composición caricaturesca por ejemplo para ridiculizar al contrario político. El manejo de los símbolos dentro de las composiciones tiene un aspecto importante para su lectura, pues se constituye en el elemento clave de la narración visual al ser el contenedor estructural de la metáfora. Aspectos como la sicología, sociología, antropología, anatomía, antropometría y política hacen parte del espectro analizado dentro de la caricatura que hace que esta tenga una fácil comprensión.

En este sentido, es clave saber que la caricatura tiene un efecto temporal. $\mathrm{Su}$ lectura solo puede enmarcarse dentro de su contexto, puesto que hace alusión a circunstancias específicas de un momento en el tiempo único, una condición social y política determinada. Hoy en día no se podría comprender una caricatura de hace un siglo sin antes conocer sus antecedentes históricos. En este caso sirve a su vez como índice documental sobre algún suceso en particular, un pedacito de la historia, claro está siempre desde un punto de vista subjetivo, puesto que es la visión desdeñosa del creador hacia su semejante. Sin olvidar que la persona dibujada debería ser reconocible por lo menos en un grupo pequeño para poder ejercer ese papel social y de crítica hacia algo convencional o cotidiano de un entorno, generando así un mayor impacto cuando más popular sea el personaje representado. Tal vez algunas temáticas de estos dibujos antiguos sean reconocibles hoy en día, en algunos casos algunas de estas caricaturas antiguas que representan aspectos sociales o políticos, son entendibles para la contemporaneidad, lo que demuestra que el país no ha podido superar muchos diversos aspectos que aquejan a la población desde tiempos inmemorables como la pobreza, violencia, corrupción, etc. El poder de las imágenes es tan grande que establecen importantes conexiones transversales en el espacio tiempo adquiriendo una dimensión histórica que abarca en sí otra forma de abordar el estudio de la historia. Tal como lo plantea el filósofo y comunicador Peter Burke (2008) en relación a la imagen histórica, "el pasado puede comunicarse por diferentes medios: una exposición, una película, una presentación oral, o simplemente un texto. Las exposiciones y las películas tienen la ventaja de que pueden hablar de imágenes a través de imágenes".

Tanto la caricatura como varios otros medios de representación visual son sinónimos de modernidad en medio del desorden y la confusión política que ensombrece los 
designios del país desde entonces. En este contexto, el periódico es otro canal de comunicación que ejerce su desarrollo en el país a mediados del siglo XIX y que no siendo empresa fácil tiene un buen número de ejemplos que evidencian una historia remota. Es de sorprender, puesto que la llegada de sistemas de impresión al país tiene un efecto retrasado, no por su adaptación técnica sino por su distribución y número de ejemplares vendidos que permitieran su propia financiación como empresa (Londoño, 1990). Para aquel entonces la mayoría del pueblo colombiano era analfabeto, es decir que el grupo objetivo principal de un periódico era reducido en comparación al panorama actual. Esta situación cambia gradualmente cuando el país se convierte progresivamente en una sociedad que pretende convertirse en industrializada, dejando su sistema económico tradicional de carácter rural. A comienzos del siglo XX se generaliza aún más la publicación de periódicos y revistas como empresas que a su vez encuentran cada vez más lectores producto de la reactivación moderada de la educación. Esta situación permite la circulación de periódicos que encuentran su supervivencia prolongada como El tiempo o El Espectador, y de revistas como Cromos, o a mitad del siglo XX la Revista Semana, esto independiente de su posición social o política en la nación. La caricatura asume mayor popularidad como medio de representación gráfica común dentro de los medios como los periódicos o las revistas. Esto lleva a que durante las primeras décadas del siglo XX se evidencie un creciente interés por los caricaturistas, lo que permite explorar otros ámbitos como el utilizarla en anuncios publicitarios. Ricardo Rendón o Pepe Mexía hacen eco de la popularidad y de la caricatura como carrera profesional no académica que permitió vivir holgadamente a sus principales exponentes. El declive en importancia para la caricatura en los medios se da a partir de la década de los sesenta del siglo XX.

\section{El reflejo artístico europeo en el pensamiento local}

Toda una serie de interrelaciones pictóricas, musicales, literarias y escultóricas que forman la importante gama de ideas modernas de las artes que cimientan las actitudes artísticas del siglo XX, se evidencian en Europa desde la mitad del siglo XIX. Es indudable que París a finales del siglo XIX y comienzos del XX albergó una serie de grandes intelectuales que proponen ideas nuevas que quiebran los estereotipos convencionales de la tradición académica. Varias generaciones de personajes que llevan una vida común marcada en muchas ocasiones por la pobreza y el exceso, 
generan un ambiente único en la condición de la mente creadora como generalidad, conocida esta como la actitud bohemia.

Está la necesidad intrínseca de cambio en el proceso artístico, el rechazo sobre lo novedoso hace de la academia algo estéril que ya no debe ser seguido y a lo cual hay que enfrentarse. Los bohemios, artistas diversos imbuidos en diferentes movimientos artísticos, componen a fin de cuentas un variado número de personas con comportamientos sociales parecidos que marcan su rumbo en el ámbito creador. En este caso la representación como canal catártico de la turbulenta vida. Los impresionistas como movimiento iniciador de esa actitud rebelde que desafía lo establecido, derrotado varias veces, luchando ideológicamente por alrededor de veinte ańos, cuando ha sido aceptado como movimiento ya era opacado por otros (Sánchez, 2005). Los llamados posimpresionistas Vincent Van Gogh, Henry de Toulouse Lautrec, Paul Gauguin, el mismo George Seurat generador del puntillismo, Paul Cezanne, fuerte influencia en los jóvenes artistas como Pablo Ruiz Picasso y George Braque (Crespelle, 1990), creadores del primer movimiento artístico considerado de vanguardia a comienzos del siglo XX, el Cubismo en 1905. A partir de esta primera propuesta radical se desencadenan una serie de postulaciones artísticas únicas por su proliferación y gesta intelectual, son el conjunto de movimientos artísticos denominados los ismos. Estos se preocupan en mayor medida a la condición filosófica del arte y del propio ser.

Estableciendo una cronología de los ismos que se generaron en las tres primeras décadas del siglo XX, se encuentran: el Cubismo como primer movimiento en 1905, y sus vertientes posteriores, Cubismo analítico (Juan Gris) y Cubismo sintético. El segundo ismo, el Futurismo en 1909. El Cubofuturismo en 1913, el Constructivismo ruso en 1914 y el Suprematismo ruso hacia 1915. El Dadaísmo en 1916. El Expresionismo alemán en 1919. El Surrealismo en 1920 y el Art Deco que se populariza a partir de la década del 20; estos entre los más destacados. Todos entrelazados, contraponiéndose, basándose entre sí generando una serie de posiciones intelectuales e ideológicas que manifiestan nuevas formas de ver y leer lo denominado como arte. 
Mientras el ambiente cultural del país, la producción artística en general tiene especialmente un auge importante en las dos primeras décadas del siglo XX, sobre todo en la región Antioqueńa; esta región en particular a nivel literario, a nivel pictórico y musical ejerce un papel sobresaliente para el prospecto académico del país, sumándose al paisaje urbano capitalino cuando varios de sus exponentes migran hacia Bogotá, como se documenta en las percepciones de la época,

"Desde fines del siglo XIX, la ciudad de Medellín entró a consolidar muchos de los procesos socioeconómicos que se venían gestando de tiempo atrás. (...) Medellín entró a ocupar dicha distinción que, más que un evento honorario, implicaba un reconocimiento de la dinámica política, económica y social que venía mostrando. En efecto, muchos de los caminos de la colonización antioqueña, en particular los que llevaban al sur y suroeste, arrancaban de Medellín. Este hecho prohijó el que la ciudad se volviese un centro comercial y un lugar de paso obligado para muchos de los viajeros que, por entonces, se aventuraban a transitar por la complicada topografía antioqueńa" (Pérez, 2001).

Precisamente estas destacadas manifestaciones provienen de estudiantes, jóvenes que se rebelan a los procedimientos clásicos de la académica artística, contagiados e influenciados por las ideas renovadoras europeas, lo ismos y su conducta provocadora. Varios autores hacen énfasis en tres generaciones de intelectuales antioqueños que aportan a la construcción de las artes en el país. Una en la primera década del siglo $\mathrm{XX}$, otra en la década de los treinta y la tercera en los ańos cincuenta y sesenta. De esta generación cuyo carácter intelectual se formaba en los talleres de los pintores, en los cafetines donde se reunían a departir los escritores de oficio y en los libros traídos del extranjero de las más controversiales obras de los filósofos y pensadores europeos, así de manera autodidacta:

"Los primeros estarían en los nacidos a fines del siglo XIX y que hacia mediados de la década de 1910 y en la de 1920 empezaron a hacer presencia en la ciudad. Uno de sus puntos de atracción estuvo en los "Panidas", grupo literario que aparece en 1915, alrededor de la revista del mismo título (ver Credencial Historia $n .^{\circ} 70$, octubre de 1995 , pp. 12-15). Allí, bajo la influencia literaria 
de los franceses, y con aire de decadentismo muy a la fin de sicle, estuvieron personajes como León de Greiff, Ricardo Rendón, Libardo Parra Toro (Tartarín Moreira), Teodomiro Isaza, Rafael Jaramillo, Bernardo Martínez, Félix Mejía, J. Restrepo Olarte, Eduardo Vasco, Jorge Villa Carrasquilla, José Manuel Mora, José Gaviria Tora y Fernando González” (Rojas, 2001).

La búsqueda de lo nuevo, lo trascendente, establece un nuevo patrón de conducta que se deriva o semeja condiciones bohemias europeas. Sin embargo, ese proceso de lo bohemio se debe entender como un entorno creador de conocimiento, generalmente empírico, autodidacta.

"No es por ende fortuito que un aire de decadencia acompañe estas manifestaciones y que sus referencias vitales y bibliográficas estén en Europa, y sobre todo en Francia. De hecho, lo que resulta sorprendente -para quienes piensan que siempre hemos sido un país, y en particular una región como la antioqueña, encerrado y sin apertura frente al mundo-, es que muchos de estos personajes que formaron la bohemia de Medellín a principios de siglo estaban al tanto de los movimientos literarios y artísticos del viejo continente, que conocían autores en sus lenguas originales (casi todos leían francés y muchos inglés) y que accedían a traducciones actualizadas de autores como Nietzsche, Schopenhauer, Sartre (en lo filosófico); Baudelaire, Rimbaud, Verlaine, Dostoievski, Wilde, Camus, entre otros (en lo literario), y que discutían temas de estética como el de si era bueno hacer o no una literatura en donde las palabras fueran objetos en sí (al estilo Mallarmé), o si era necesario que estas sirvieran para hablar al hombre común" (Pérez, 2001).

Tanto en Medellín como en Bogotá los círculos artísticos tenían como base los cafés y los bares de la ciudad. Esta tradición tertuliar se condensa en algunos sitios estratégicos como La Gran Vía o El Automático en Bogotá. Grandes pensadores y escritores estaban entre sus clientes más asiduos como Tomás Carrasquilla (padrino y maestro de Pepe Mexía), Guillermo Valencia o Ricardo Rendón. Precisamente Rendón y Félix Mejía Arango se nutren de estos lugares, se conocen mutuamente y generan los contactos claves para el desarrollo de sus posteriores carreras. De los encuentros, discusiones e inquietudes surge el primer movimiento colombiano que 
podría decirse contiene la vanguardia artística en el país: los Panidas, constituido en Medellín por un grupo de trece jóvenes dibujantes, pintores, escritores y poetas como el afamado Guillermo León de Greiff. Tomando como referencia la conformación de los movimientos modernos extranjeros, matizan y fusionan accionares y características claras de varios de estos ismos. Por sus rasgos como grupo, y sus consecuencias escritas y pictóricas se puede entrever la influencia del Futurismo italiano, contemporáneo en tiempo y forma, es decir, la manera de asumir y de mezclar la literatura y la pintura de manera simultánea (figura 1). Por supuesto el Futurismo es en mucho más agresivo, sin embargo, conservan la connotación del escándalo social, del quebrar las reglas impuestas del crear y el análisis de la forma pictórica tratando de esquematizar las formas percibidas.

Figura 1. Revista Pánida

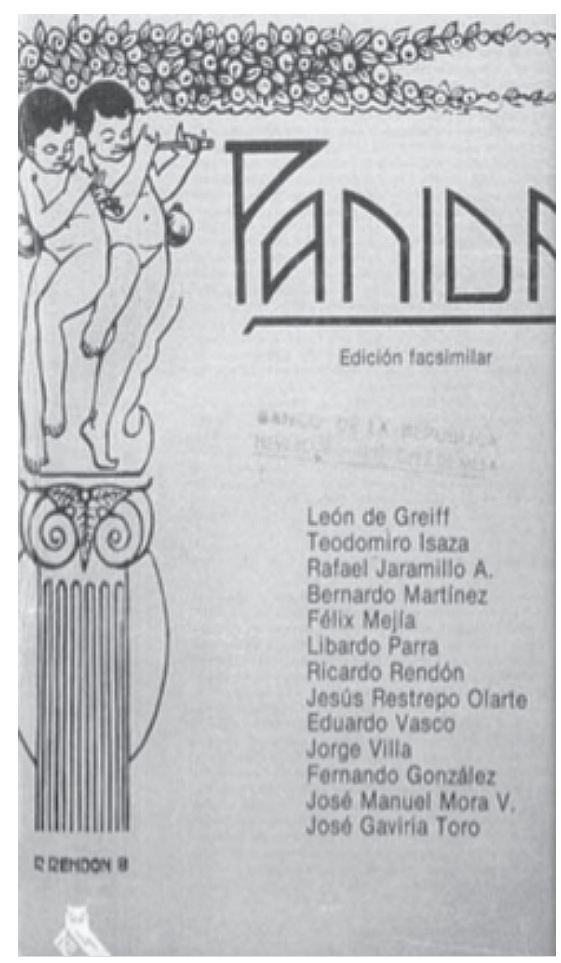

Fuente: Biblioteca Nacional de Colombia. Diseño Ricardo Rendón (1915). 
Un factor importante en la difusión del pensamiento futurista queda reflejado y apropiado entre las manifestaciones idealistas del grupo representado en su manifiesto al mejor estilo de los ismos. Dicha contrariedad a las normas moralistas de la sociedad colombiana para aquel entonces queda en evidencia, como lo comenta Escobar Calle en su crónica histórica desde la perspectiva literaria:

"El día 15 del mismo mes circuló el número uno y el efecto inmediato fue triple: los Panidas celebraron con tremendo alboroto en la sede principal (el Café El Globo) y en las subsedes (el Chantecler y La Bastilla); los lectores escandalizados echaron pestes contra los versos raros de corte modernista de un tal Leo Le Gris, que cantaban a la luna lela y a los búhos "que decían la trova paralela; y La Familia Cristiana, órgano oficial de la curia, se dejó venir con el consabido veto, censurando la revista y prohibiendo su lectura a los adolescentes "por sus efectos perniciosos" (1995).

Estaban en sus huestes tanto literatos que pintaban o pintores que escribían. En estos últimos son evidentes Ricardo Rendón y Félix Mejía Arango. Este grupo, aunque se conoce desde su aporte a la literatura, realmente ejerció una acción interdisciplinaria, polifacética y eclética. Así, sustentados en argumentaciones basadas en Nietzsche y el simbolismo, además auspiciados por mecenas de la talla de Carrasquilla, los Panidas serán rebeldes, agresivos desde sus postulaciones artísticas que se convierten en un fuerte referente en la historia del país conocidos posteriormente como la generación de Los Nuevos (Escobar, 1995).

La revista creada por el grupo, llamada igualmente Panidas, en 1915 se constituiría en sí misma el manifiesto del movimiento. El diseño gráfico, es decir, la diagramación, las formas decorativas o vińetas diagramáticas y la selección de fuentes tipográficas de todos los números de la revista fueron hechos por Ricardo Rendón; Félix Mejía, al contrario, se dedicó a ser director y parte del comité editorial de la misma. Al igual que los dadaístas, unos años más tarde la revista sirve de órgano difusor de sus ideales $\mathrm{y}$ de sus creaciones. 
Es en Medellín confluyeron estos artistas que compartieron instrucción en el recién creado Instituto de Bellas Artes de 1910 a 1911, y que trazaron tras de la disolución del grupo de los Panidas dos carreras exitosas en el ámbito artístico.

"Y sin duda que lo lograron con la maravillosa poesía del mismo de Greiff, y con la obra filosófica y ensayística de Fernando González, y con la vanguardia clandestina que significa la obra artística de Rendón, y de Mexía cuyos monigotes de un subido modernismo formulan una propuesta "emparentada con el Dadaísmo”, según juicio del crítico de arte Álvaro Medina. No cabe duda que fue el ímpetu de los Panidas el que comenzó a insuflar aires de modernidad en el arte y en la literatura colombiana. Fueron ellos quienes iniciaron la Contemporaneidad. Con ellos aparece la Modernidad, al buscar las nuevas ideas y las nuevas formas en antecedentes inmediatos (Nietzsche, Simbolismo, Art Deco, Bauhaus, Cubismo, etc.). Pero es una "modernidad" donde aclimatan lo exótico, lo foráneo, lo adaptan, lo vuelven criollo, les sirve de "utensilio de trabajo" y no de modelo calcable. Asimismo, a partir de los Panidas esas dos vertientes que seńala Luis Vidales como constantes en la literatura y en el arte colombiano, la oficial y la subterránea, no solo ahondan y amplían sus diferencias, sino que la segunda se hace evidente, palmaria, abierta, trasgresora" (Escobar, 1995).

\section{Ricardo Rendón (1894-1931)}

Ricardo Rendón nace en Rionegro, Antioquia, al parecer solo tuvo instrucción artística y académica en el Instituto de Bellas Artes durante un breve tiempo y en el taller del maestro Francisco A. Cano. Por lo demás su formación se debe a una condición autodidacta. Con un genio nato para el dibujo, Rendón fue gratamente referenciado por sus contemporáneos con el título de maestro a muy corta edad, apenas pasados los 30 años. Incluso antes de ingresar como diseñador a la revista Panidas ya había comenzado su trabajo en publicaciones periódicas. La Revista Avanti de 1912 consigna 16 caricaturas e ilustraciones (Escobar, s.f.). Trabaja para el periódico El Espectador en Medellín, donde diseña, diagrama e ilustra una separata llamada La Semana hacia 1915. Igualmente empieza a publicar sus caricaturas en el 
diario La República. Crea fama en Antioquia a través de estos medios y finalmente decide trasladarse a Bogotá.

Figura 2. Portada periódico El Tiempo. 1 de enero de 1930

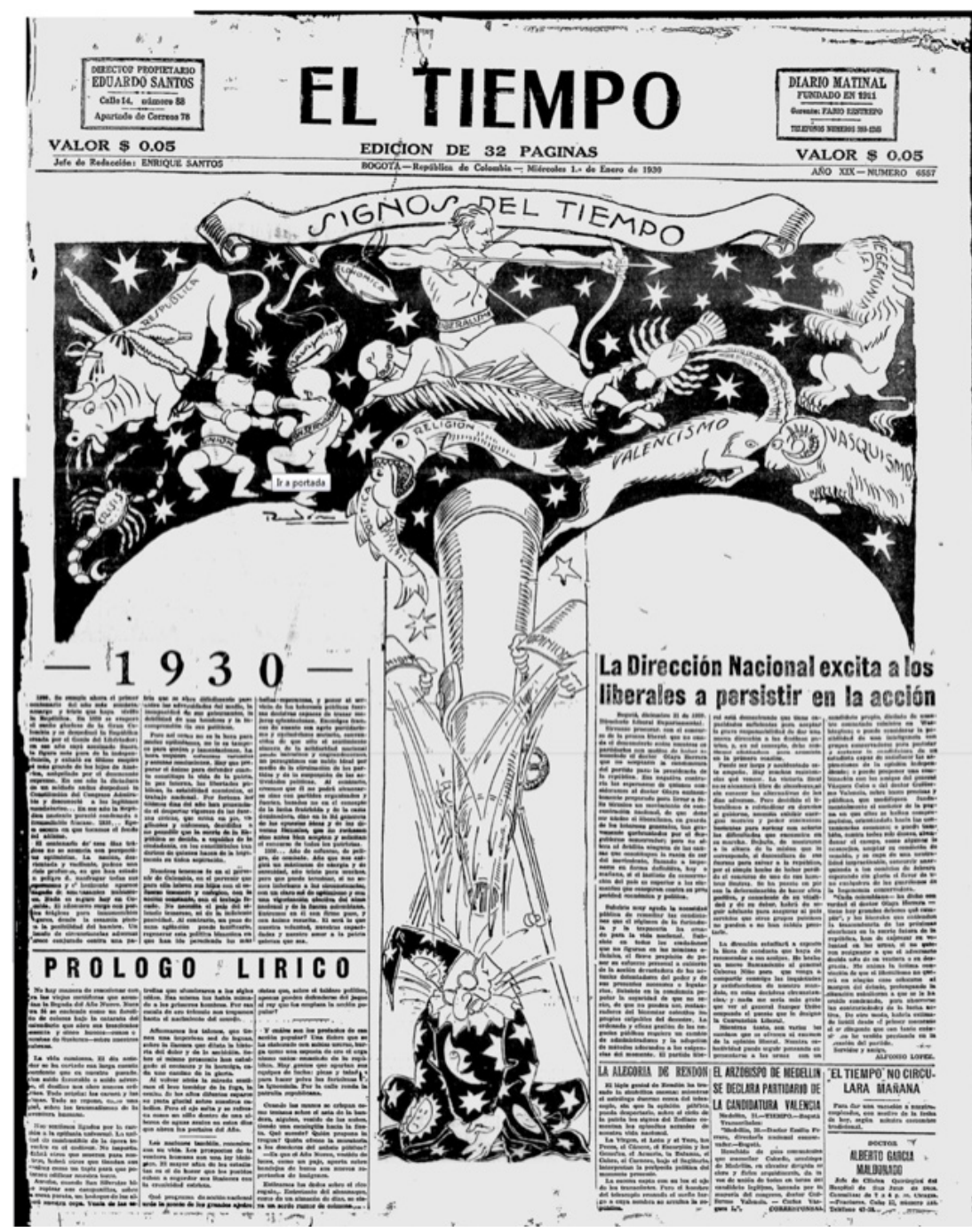

Fuente: Archivo digital El Tiempo. Diseño y diagramación: Ricardo Rendón 
Allí se consolida definitivamente, trabajando desde las publicaciones periódicas más prestigiosas del país, primero como caricaturista y luego como diagramador. La revista Cromos, la revista Avanti, la revista El Gráfico, el diario La República, son también ejemplo de ello. Así como diseñador de titulares y ornamentos ilustrados para El Tiempo (figura 2) y posteriormente trabajando como diseñador de anuncios publicitarios para múltiples marcas como Chevrolet, Gaseosas Posada Tobón o Zarcol. Todas estas identificables por el estilo gráfico de Rendón pero que no han sido todavía registradas o clasificadas. Uno de los trabajos más significativos de su corta carrera fue el realizado para la empresa Coltabaco (figura 3).

Figura 3. Anuncio Revista Sábado. Diseño de isologo por Ricardo Rendón

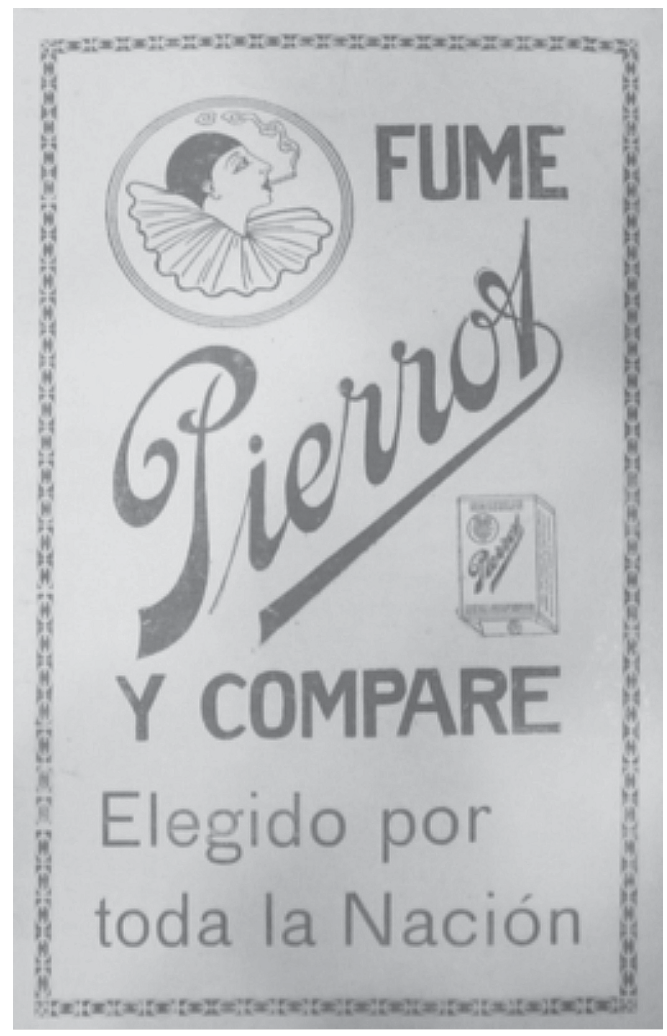

Fuente: Revista Sábado, 1921 
Esta empresa fue al parecer la primera que dentro de su estructura administrativa creó un departamento de publicidad donde trabajaban un equipo de artistas realizando todo el desarrollo de piezas gráficas para la gran variedad de productos. Destacan dos trabajos que tuvieron trascendencia para aquel entonces: la realización de la identidad visual para la marca de cigarrillos Victoria, que incluyó la elaboración de una serie de doscientas postales coloreadas a mano (Rendón, 1920), que se distribuían como un álbum en puntos de canje o venta y que tuvo una popularidad tan grande que incluso se llegaban a coleccionar e intercambiar como un bien preciado. El segundo, es la propuesta visual y el desarrollo igualmente de identidad visual para la marca de cigarrillos Pielroja. Junto con el otro diseñador artista Miguel Ángel del Río, realizan dos propuestas de diversa índole estilística que de manera altercada serán publicados e impresos, primero el diseńo de del Río que plantea un Pielroja montado en su caballo y cierto tiempo después el de Rendón que desarrolla el conocido hoy retrato del Pielroja de perfil.

Figura 4. Diseño de imagotipo y diagramación. Ricardo Rendón

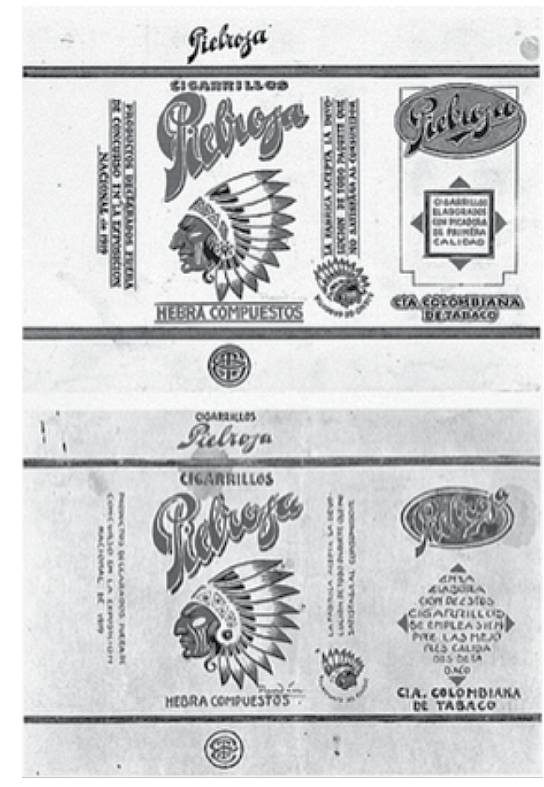

Fuente: Registro Visual Nelson Pabón, 1925 
Para finales de la década del veinte, Rendón tuvo su mayor fama hasta el punto de traspasar fronteras. The New York Times estaba interesado en que trabajara para ellos, pero su ánimo estaba encadenado a la vida nacional y la bohemia bogotana, instaurada en la generación que por aquel entonces figuraba una conducta idealista que semejaba a los contextos parisienses o berlineses. Como lo anota en su investigación el maestro Escobar Calle:

\begin{abstract}
"Esas labores alternas de ilustrador y dibujante publicitario le servían a Rendón para reforzar sus ingresos, que luego generosamente derrochaba en la bohemia bogotana. En marzo de 1928 El Tiempo lo contrata como caricaturista con exclusividad remunerada, "pagándole cada trabajo a treinta pesos -cuenta Fraylejón-, aunque la mayor parte de las veces su paisano Fabio Restrepo las subía a cincuenta”. Rendón, entonces, pasó a ser el dibujante mejor pagado del país, pues sus entradas -sumados los contratos extras por publicidad, ilustraciones y diseño de carátulas de libros-, en ocasiones ascendían a más de mil doscientos pesos mensuales, "en esos tiempos en que el presidente de la República se ponía mil quinientos duraznos y los congresistas, quinientos". Por eso en épocas en que el peso estaba a la par del dólar, Rendón se dio el lujo de rechazar jugosas ofertas de The New York Times y de la revista Caras $y$ Caretas de Buenos Aires. En ambas ocasiones arguyó que estaba dispuesto a pagar el doble con tal de quedarse en Bogotá: "Yo gano aquí mil y pago otros mil por no tener que vivir en Nueva York", fue la respuesta que dio a Samuel H. Piles, embajador de Estados Unidos en Colombia” (Escobar, 1995).
\end{abstract}

Rendón se convirtió en todo un personaje público, la fama y el dinero se lo debía a su talento, el país lo conocía y era un crítico politólogo del momento. Cuando ocurre la Masacre de las Bananeras, gracias a sus caricaturas publicadas paralelamente a la investigación por parte del doctor Jorge Eliecer Gaitán este suceso no pasó inadvertido para el país. Sin embargo, a pesar de su multifacética producción, hoy en día solo el aspecto de la caricatura se hace visible, olvidándose sus aportes a las artes y al diseño gráfico colombiano.

Aunque el término de diseñador gráfico se acuña en los años treinta en Estados Unidos para designar un oficio en particular, sí se conocía el área del dibujo 
publicitario como etiqueta para describir las áreas que hoy se conocen como diseño gráfico. El hecho de que el término para designar una profesión no fuera efectivo para su tiempo, no quiere decir que no existiera. A Rendón lo podemos catalogar como un diseñador gráfico, que se hace famoso en el país y vive de su otra gran habilidad, la caricatura. Al obtener reconocimiento como dibujante caricaturista, se le ofrecen diferentes oportunidades para poder complementar sus diversos oficios y finanzas: la publicidad. El dibujo publicitario como se conocía en ese momento o el diseño gráfico publicitario como se establece hoy.

El estilo compositivo de Rendón combina la destreza y característica única de su caricatura, esquemática, fuerte en representación de carácter, trazo seguro, estilización de la forma, tendencias similares al Art Deco en su configuración humana, una tendencia a la estructura formal del retrato como el de Amadeo Modigliani, con el mensaje publicitario de grandes compañías. Esta fusión le da su originalidad, frente a las demás manifestaciones de diseño del momento. Incursiona en el desarrollo de identidad corporativa para el legendario ya cigarrillos Pielroja, y el diseño de las cajetillas de cigarrillos Victoria para Coltabaco. Sus diseños para cupones Posada Tobón (Postobón) que llegaron a ser tan populares que las personas no reclamaban su premio con los cupones sino que los coleccionaban. Al mismo tiempo era ilustrador, en este caso remite una representación particular que obedece a un texto específico. Es decir que no es sinónimo de caricatura. Era ilustrador como lo son muchos de los diseñadores gráficos del mundo. Rendón es el caso del primer diseñador colombiano famoso a nivel internacional, The New York Times con su extensión de contrato de exclusividad y otras publicaciones de España y Argentina lo solicitaban y colocaban como uno de los mejores de América en la década de los veinte. Su temprana muerte, a los 37 años de edad por suicidio, causó titular de plana completa de los principales diarios, múltiples homenajes y reseñas a lo largo de la historia.

\section{Pepe Mexía, seudónimo de Félix Mejía Arango (1894-1978)}

Nace en Concepción, Antioquia, fue durante su vida un multifacético creador, abordando áreas del conocimiento fuera de las artes. Empieza su vida artística e intelectual como uno de los gestores o fundadores del grupo los Panidas, junto al poeta León de Greiff. Es literato por vocación mas no por profesión. Su tío político 
y mentor fue el escritor Tomás Carrasquilla. A excepción de su breve paso por el Instituto de Bellas Artes de Medellín junto a Rendón, y teniendo en cuenta su multiplicidad profesional, se considera un autodidacta. $\mathrm{Su}$ nombre se encuentra relacionado con diferentes disciplinas que forman su carácter intelectual, sin embargo, su pasión fue la arquitectura, sus obras arquitectónicas las realizó sin tener algún estudio académico, la iglesia del Perpetuo Socorro y de San Miguel en Medellín son algunas de sus más prestigiosas obras. Otra de sus vertientes profesionales lo lleva a la política, sus logros: ser alcalde de Medellín y senador de la República. Fue historiador y dejó su huella en la investigación y datación a nivel antropológico en varios textos importantes como Apuntes sobre arqueología 1 y 2, instrumentos de piedra (1938) (Piazzini, 2016); El cementerio indigena de la Cimitarra (1944); Estudios indigenas colombianos (1939) y Manifestaciones artisticas de los indigenas de Colombia (1946). Escribió en revistas como la de la Universidad de Antioquia, Boletín de Arqueología y Repertorio Histórico (Banco de la República, s.f.). Como dibujante y caricaturista, ejerce una fuerte influencia como generador de lenguajes gráficos o pictóricos novedosos. Sus características en la realización de caricaturas e ilustraciones tienen una esquematización suprema, fina y diestra en su construcción. Uno de los rasgos que caracterizan sus representaciones son el agudo análisis de la sicología del personaje, el arte de transmitir condiciones de conducta que en muy pocos trazos generan una inmediata comprensión, hacen de su trabajo igualmente al de Rendón algo único y sobresaliente en el panorama gráfico del país.

"Por aquella época era ya usual la presencia de sus ilustraciones en otras publicaciones entre las que se recuerda Revista Colombia (1916-1921), Sábado (1920-1923) y los periódicos El Espectador, El Bateo, El Correo Liberal y Colombia. Aparecen en ellas los primeros "juncos" o sea la representación muy personal y estilizada, en poquísimas líneas, de las figuras -principalmente la humana- como expresión de estudios sicológicos de la personalidad, las costumbres y las circunstancias de la vida diaria. Esto fue radicalmente novedoso y original y coloca a Pepe Mexía como el introductor de las corrientes de vanguardia en Colombia. La economía del dibujo, la depuración de la línea y la agudeza de la observación sicológica son sorprendentes. Este sería el principal punto de partida para mucha de su producción posterior" (Banco de la República. Biblioteca Luis Ángel Arango, 1986). 
El "junquismo" resulta ser la denominación que se le asigna al estilo visual logrado por Mexía, su esquematización máxima hace que con muy pocos trazos realice composiciones significativas. En voz de los críticos, parecían un montón de "juncos", de donde deriva su nombre.

Figura 5. Artículos sobre el "junquismo"

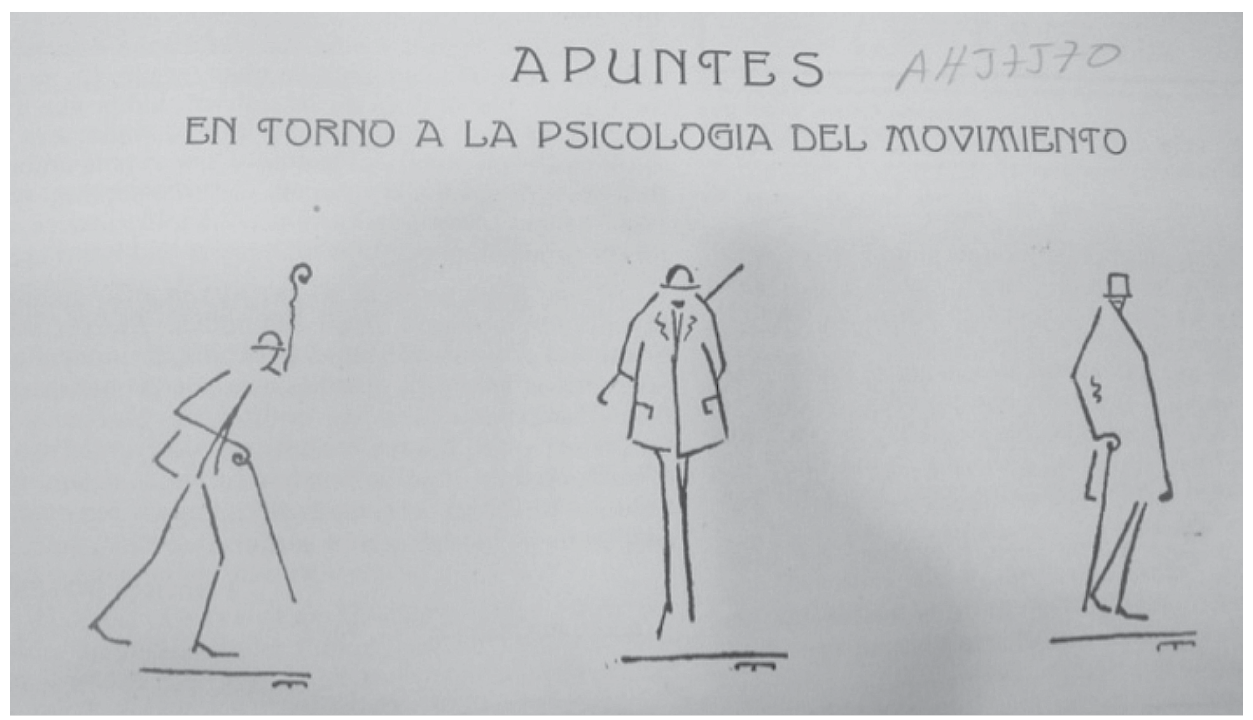

Fuente: Revista Sábado, 1921

Resulta que este "junquismo" sería un estilo visual implementado por Mexía que contendría las características pictóricas de un corte modernista. La casi abstracción de sus representaciones, ya desde comienzos de los veinte, serían paralelos al proceso abstraccionista de los movimientos europeos. Paradójico es que Mexía logra viajar a las ciudades europeas importantes para contemplar sus obras, pero ya a una edad avanzada, ocasión que aprovechó para estudiar las obras de Picasso. Sus trabajos realizando ilustraciones para medios editoriales sitúan a Pepe Mexía como diseñador gráfico (figura 6), al incursionar no solo en el dibujo sino en la creación de tipografías para sus trabajos, en la diagramación limpia y contundente de sus carátulas para libros y revistas, siempre acompañados de sus rasgos "junquistas” particulares. 
Figura 6. Carátula de libro. Diseño Pepe Mexía

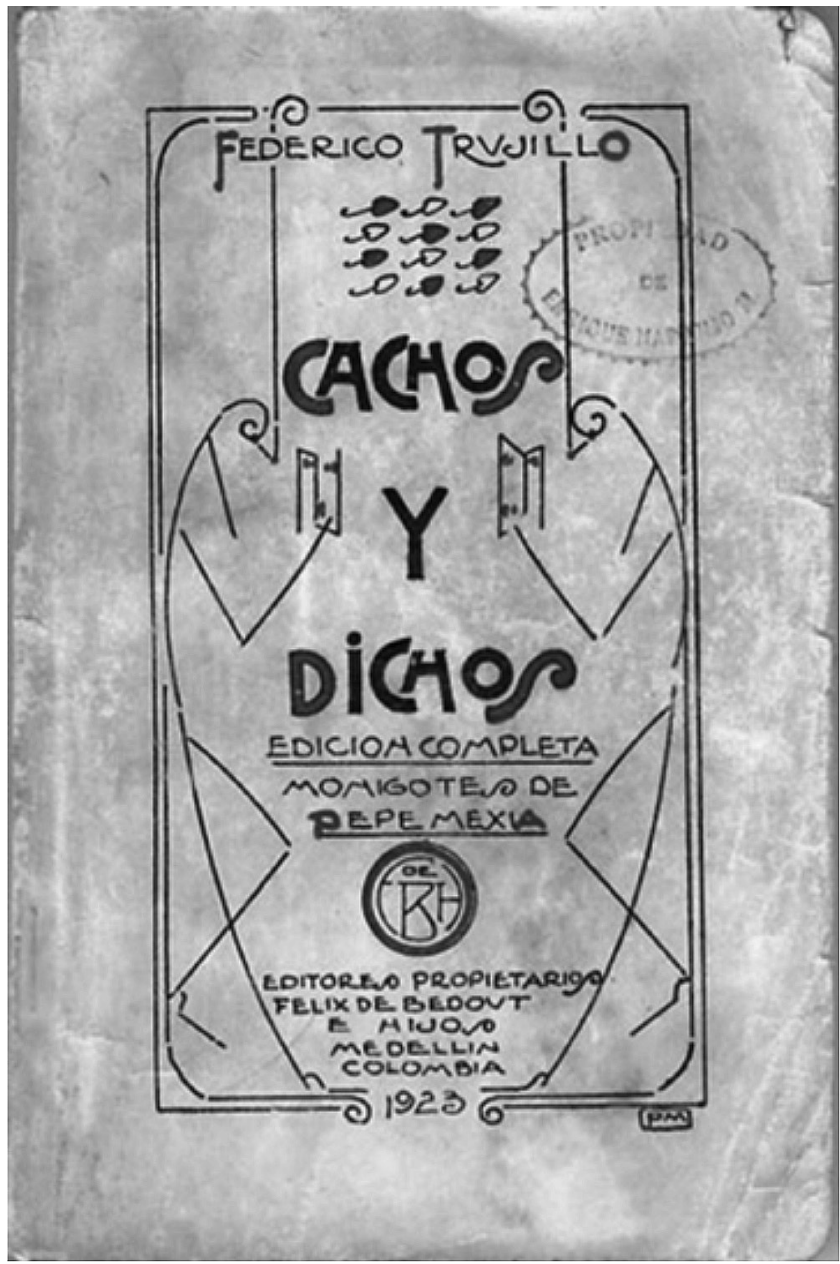

Fuente: Recuperado de kaaterskillbooks.com, 1925

Difícil es seguir su trabajo, pues hay que indagar en los aportes a la antropología en Antioquia, su obra como ingeniero civil y arquitecto, como poeta, escritor o dibujante, así como caricaturista o artista plástico y como político destacado. 


\section{CONClusiones}

\section{La historia del diseño no promulgada}

Aún no existe un libro publicado sobre la historia del diseño en Colombia. Los textos que hacen referencia a este particular son pocos y en su gran mayoría enuncian que el diseño gráfico en nuestro país nace a partir del año 60 del siglo XX con Dicken Castro y David Consuegra, quienes traen al país el oficio del diseñador gráfico académico. De hecho existe un intento por escribir la historia del diseño gráfico en Colombia iniciado por el mismo Castro a modo de manuscrito, texto que hoy se encuentra en la Biblioteca Luis Ángel Arango, pero que se queda corto en la descripción de los fenómenos aquí expuestos o en tal caso ni siquiera se nombran (Castro y Beltrán, 1997). El propósito de este artículo es evidenciar la presencia de diseñadores gráficos importantes durante la primera mitad del siglo XX y recordar sus aportes más significativos. Ellos sirvieron de referencia a varios diseñadores, una generación más adelante como lo fue Sergio Trujillo Magnenat, más conocido por su pintura que por su trabajo de corte Art Deco en el diseńo gráfico y de su actitud profesional influenciada en la escuela de diseño alemán Bauhaus.

Ricardo Rendón nos deja su estilo particular de mezclar rasgos caricaturescos en la gráfica publicitaria, que fueron exitosas soluciones de comunicación gráfica en su momento. Pepe Mexía, un legado sin precedente tanto en el diseño como en la arquitectura, antropología y la literatura. Sus estudios combinados de estas ramas del saber tienen como conclusión un estilo visual único que hoy por hoy es olvidado históricamente. Un diseñador integral, que maneja varias áreas del conocimiento, es un fiel prototipo actitudinal del diseño europeo propio de los años 20. Este tipo de creador se manifiesta a finales del siglo XIX y posterior, por ejemplo, en la escuela de diseño Bauhaus o en los ismos artísticos como el Constructivismo ruso. Es el primer diseñador o artista directamente interesado en datar y estudiar el diseño precolombino en el país. Este interés constituye un legado intelectual fuerte seguido por los estudios e influencias del diseńo antiguo americano aplicado por futuras generaciones de diseñadores hasta los años 70, como Dicken Castro y sus logotipos, David Consuegra y Antonio Grass. Como se concluye en el trabajo de Jorge Ochoa Ochoa: 
"Por otro lado se evidencia un surgimiento de modernismo gráfico y conceptual, con revistas como Arte (1913), y Panida (1915), dirigidas por artistas como Pepe Mexía, Sergio Trujillo Magnenat, Ricardo Rendón, José Posada Echeverri, entre otros, las cuales nos ofrecen un acercamiento a las vanguardias surgidas en Europa, haciendo precozmente arte contemporáneo en Colombia, pues se constituyeron en un grupo que irrumpió con propuestas visuales poco conocidas hasta ese momento, llegando, incluso, a emparentarse con movimientos tan contundentes como el Dadaísmo, el Expresionismo o el Surrealismo" (Ochoa, 2010). 


\section{REFERENCIAS}

Banco de la República. Biblioteca Luis Ángel Arango. (1986). Pepe Mexía. Colombia prehispánica. Regiones arqueológicas. Bogotá: Instituto Colombiano de Antropología e Historia. Macizo central antioqueño. Recuperado de http://www.banrepcultural.org/ blaavirtual/arqueologia/prehisp/cp24.htm

Burke, P. (2008). La historia imaginada: construcciones visuales del pasado en la Edad Moderna. En J. Lluís, y D. Carrió-Invernizzi (Eds.) Madrid, España: Centro de Estudios Europa Hispana.

Castro, D. y Beltrán, O. (1997). Historia del diseño gráfico en Colombia: tercer informe de avance. Bogotá.

Crespelle, J. P. (1990). La época de los impresionistas. Buenos Aires: Javier Vergara Editores.

Escobar, M. (1995). Los Panidas en Medellín, crónica sobre el grupo literario y su revista de 1915. Revista Credencial Historia.

Escobar, M. (s.f.). Ricardo Rendón, una ausencia temprana. Biblioteca Virtual de Antioquia. Recuperado de http://web.archive.org/web/20031014092029/http://biblioteca-virtualantioquia.udea.edu.co/pdf/4/4_224397081.pdf

González, B. (1989). Historia de la caricatura en Colombia. Bogotá: Banco de la República.

Jambrina, P. (Dirección). (1926). Garras de Oro [película]. Colombia. Recuperado de http:// www.filmaffinity.com/es/film358968.html

Londońo, S. (febrero de 1990). Periódicos manuscritos del siglo XIX en Antioquia. Biblioteca virtual Luis Ángel Arango. Recuperado de http://www.banrepcultural.org/blaavirtual/ revistas/credencial/febrero1990/febrero1.htm

Ochoa, J. H. (2010). Influencia de los movimientos artísticos en el diseño gráfico colombiano. Dialéctica Revista de Investigación, (26), pp. 108-115. 
Pérez, V. (2001). La bohemia de antaño en Bogotá y Medellín. Personajes, cafés y ocurrencias alcohólicas y poéticas. Revista Credencial Historia, No. 142.

Piazzini, C. E. (2016). Los académicos de principio de siglo XX. Aproximación al proceso de regionalización de la antropología en Antioquia (1850-1970). Medellín: Universidad de Antioquia.

Rendón, R. (1920). Álbum de caricaturas de los cigarrillos Victoria. Bogotá: Biblioteca Luis Ángel Arango.

Revista Semana. Universidad Nacional de Colombia. (2010). Colombia, 200 años de identidad: 1810-2010, en busca del progreso: 1860-1909, volumen III. Bogotá: Publicaciones Semana y Universidad Nacional de Colombia.

Rojas, M. B. (2001). Cantar de amigos y copas. Notas sobre el Medellín bohemio. Modernidad, sentido urbano y periodización de la bohemia. Revista Credencial Historia, 142.

Sánchez, C. (2005). Claude Monet, los reflejos de la luz. Bogotá: Panamericana Editores.

Stara, D. (2009). La restauración del color en el cine mudo: del desmetcolor a la restauración digital. Cuaderno de Documentación Mutimedia, (20), pp. 43-74. 